\title{
Reconciliation ecology, from biological to social challenges
}

L'écologie de la réconciliation, du défi biologique au défi social

\section{Denis Couvet and Frédéric Ducarme}

\section{(2) OpenEdition}

\section{Journals}

Electronic version

URL: http://journals.openedition.org/ethnoecologie/1979

DOI: 10.4000/ethnoecologie. 1979

ISSN: 2267-2419

\section{Publisher}

Laboratoire Eco-anthropologie et Ethnobiologie

\section{Electronic reference}

Denis Couvet and Frédéric Ducarme, «Reconciliation ecology, from biological to social challenges », Revue d'ethnoécologie [Online], 6 | 2014, Online since 31 December 2014, connection on 05 May 2019 URL : http://journals.openedition.org/ethnoecologie/1979; DOI : 10.4000/ethnoecologie.1979

This text was automatically generated on 5 May 2019.

\section{cc)}

Revue d'ethnoécologie est mis à disposition selon les termes de la licence Creative Commons Attribution - Pas d'Utilisation Commerciale - Pas de Modification 4.0 International. 


\section{Reconciliation ecology, from biological to social challenges}

L'écologie de la réconciliation, du défi biologique au défi social

Denis Couvet and Frédéric Ducarme

\section{Introduction : Biodiversity alterations and reconciliation ecology}

1 The most common representation of « nature » or « biodiversity » is often big charismatic animals like tigers, whales or remote wildernesses such as African savannahs (Ballouard et al. 2011). Threats of losses of such biodiversity have been of primary concern, especially as they are irreversible. Genes and species on the verge of extinction have been at the forefront of biodiversity conservation policies. A major policy trend in this domain has been the creation of protected areas. Such conservation policies have had some success, reducing the rate of species loss (i.e. Rodrigues 2006), although much improvement is necessary and possible (see Venter et al. 2014).

2 However, people's actual contact with biodiversity passes more often through what can be called " ordinary biodiversity", which represents all the everyday, non-spectacular, landscape species and ecosystems. Ordinary biodiversity changes and is actually altered, in regards to birds, pollinators, amphibians, corals... in all types of habitats (Pereira et al. 2012, Dirzo et al. 2014). Such changes are often rapid (e.g. Dornellas et al. 2014), with major systemic changes associated, such as species range shifts (Pereira et al. 2012), phylogenetic diversity (Friskoff et al. 2014), or specialization loss (Devictor et al. 2008). Such alteration could impact major ecological functions e.g. Dirzo et al. 2014), and in consequence endangered species and human societies, which both depend on ordinary biodiversity.

3 To halt such alteration, the core of human activities has to be modified in every ecosystem, taking care of two major sources of biodiversity alterations, losses, 
fragmentation and disturbance of habitats. The necessity, hence the objective, is that human activities become compatible with the maintenance of the major properties of ordinary biodiversity, in every ecosystem. Such a guiding principle can be named 'reconciliation ecology', a terminology coined by M. Rosenzweig (2003). Indeed, decreasing human pressures locally, alleviating the local effects of global pressures -for example climate change-, is not enough.

The present paper aims to examine the major biological and social questions arising for reconciliation ecology. From the biological viewpoint, the purpose is to describe alterations, to determine biophysical causes. That requires in particular assessing the biodiversity units concerned. These are populations, communities, ecosystems, rather than species.

In a second part, starting from the perspective of reconciliation ecology, we will examine how to frame the relationship between societies and biodiversity, so that the fate of ordinary biodiversity matters when public policies are considered. We will go from the more pragmatic viewpoint, devising public policies, to the more encompassing viewpoint, considering the social norms which support such policies. We distinguish three social issues that reconciliation ecology ought to consider, 1) devising core principles of public policies preventing the loss of ordinary biodiversity, depending on the logics of human activities and social decisions, 2) defining biodiversity values, addressing different actors values and representations, necessary to justify policies whose ambition is to maintain restore, ordinary biodiversity, 3) examining the adequacy between social norms and biodiversity values. In this regard, we will examine the possibilities brought by the capability approach (Nussbaum 2000).

\section{Biological issues}

6 The exact scientific definition of ordinary biodiversity is still under discussion, for ecological as well as for social sciences, but almost always connects scales of thinking, from the species level to ecosystems and landscapes. It is most often addressed through " ordinary species", which are easier to define, mark out and inventory (for example on the basis of the IUCN red-list of threatened species), as neither rare and/or endangered, neither domesticated, neither exploited. Taken thus, ordinary species bring together up to $80 \%$ of vertebrates, with a lower proportion for some highly threatened groups like big carnivores or cetaceans. However, ordinary biodiversity must not stop at enumeration of species, but must include all the ecosystem processes that come along.

\section{Biological reasons to preserve ordinary biodiversity}

7 So why should ordinary biodiversity concern conservation ecologists whereas these are the species least threatened by extinction? A first reason is that protected, charismatic and endangered species actually rely on this ordinary biodiversity: conserving tigers is useless if their habitats shelter no more prey species (themselves reliant on a variety of plants; themselves supported by pollinators, etc.). Abundance and diversity of ordinary species constitute the basis upon which rarer, more complex or more specialized species will manage to establish in natural systems. Ceteris paribus, the more a species is abundant, the more links it can establish with other species; then the abundant species becomes a sort of hub species, linking preys, commensals, parasites, predators and other 
associated species. In other words, the fate of ordinary species determines the viability of endangered species. Such an idea is well known for highest trophic level species, especially carnivores, with the idea of « trophic pyramid, » each level relying on another which must be far more abundant. In the same way, perturbation on lower trophic levels - generally made of ordinary species - can affect the entire trophic network.

For the same reason, ordinary biodiversity can act as a sentinel for biodiversity. Ordinary species are more likely to be compatible with human activities than endangered species, which can become cryptic, like the lynx. As human influence spreads, kulturmeider must flee to remoter places, and they are often very difficult to survey. Thus, when the interactions between species get known better, cryptic species can be followed through ordinary species, which can be their predators, competitors, prey, symbionts, or a common host to the same parasites. Thus, if we understand species interactions, we can assess the global state of the ecosystem without having to survey all species individually, and then the probability of presence of some hardly-seen species can be inferred. Just like the visible part of an iceberg, ordinary biodiversity is the visible part of total biodiversity, and a slight decrease in such species can be the sign of a wider threat for other species, and then trigger a specific conservation program.

9 A good indicator community needs for the density of the interactions it establishes with other groups (called "connectance») to stand also for their own dynamics and coevolution : only then is the state of this community representative of the state of other non-surveyed communities. In this regard, common birds is a widely used biodiversity indicator in Europe (with the STOC program in France for example), as such animals are easy to spot, identify and follow, but also consist in a huge number of abundant species, representing a wide part of ordinary biodiversity, therefore quite a robust indicator (Julliard 2004). Moreover, most non-game species are not subject to direct human pressures, unlike big carnivores, which reduces potential biases. Hence, variations of abundance in highly specialized species have been observed in the STOC dataset, showing a decrease in ecosystem complexity due to the biotic homogenization of European ecosystems (we will discuss later this functional aspect). Even if this approach proved useful and is widely used, one weakness of the use of sentinel groups is that it may entail superficial measures improving only the state of this particular group, and thereby constitute a deceptive proxy in certain cases. Artificial nesting sites or feeding can have this effect, leading to an artificial good state of some isolated species without giving any clue about the local environment. This forces scientists to cross many different indicators to get valuable data.

10 Another reason to consider ordinary biodiversity in ecosystems where charismatic or endangered species are absent is the fact that their fate, the decline or the increase of some of them is also a risk for ecological systems, including human societies (Pereira et al. 2012). As ordinary species often live close to human activities, they are therefore exposed directly to perturbations and threats. Populations can be extirpated at a very high rate (Hughes et al. 1997). A single population extinction might be less dramatic and mediated than species extinction; however, such extinction affects the local ecosystem, representing a step towards extinction, through genetic impoverishment and range shrinking. Today's ordinary species may hence be tomorrow's endangered species: the sooner scientists detect a decrease, the easier it is to prevent it. Moreover, such population extinction might affect the fate of interacting species, through losses of ecosystem functionalities. This is currently the case in Europe, where scientists observe a 
decline of diversity and abundance of many communities of common birds and plants. This leads to the weakening of all the related communities and threatens not only the ecosystem itself, but also people and activities that depend on it. The pollination shortfall observed in agriculture for several decades, the decline of water purification capacities of catchment basins ${ }^{1}$, the threats hanging over pest control (Boyles et al. 2011) or large ungulate control, are all results of such chain reactions. Current major changes in the state of numerous vegetal or animal communities and their biotic homogenization are hence drivers of risk for both biodiversity and human activities.

\section{The relevance of communities, of their properties}

11 As all species are deeply interrelated in an ecosystem and are all subject to global change (Pereira et al. 2012), when biodiversity is at stake, endangered species must not be the only lens through which we view the crisis. More than a binary count of extant or extinct species, communities' characteristics (such as diversity or variations in abundance) allow them to get different yet useful information. Communities can be seen as biological objects, in charge of mechanisms and functions; for example the Marine Trophic Index evaluates the state of a marine ecosystem through the main trophic level of fish catches, a lower level being the sign of a decrease in predators, then of an over-exploitation of the ecosystem.

12 Two useful levels of analysis can hence be the population level and the community level. The first aims at considering only the local headcount of a selected species, apart from its global abundance and range: just like a species, a population can, locally, be threatened or disappear, and its variation can be monitored. On the other hand, the idea of community encompasses different definitions, varying in their spatial and biological dimensions. It can either represent the total local pool of species populations, their abundance, functions and relations, or a specific bunch of species that share the same function in the ecosystem, like pollinators, insectivore birds, big herbivores or decomposers. For most communities, the more abundant its population, the more it affects ecosystem functioning. Then, the reduction in abundance of a once-common community, even without species or population extinction threat, can have large ecosystem effects like trophic changes, and especially trophic cascades. For example in Yellowstone, a minor replacement of the local trout Oncorhynchus clarkii by another species (Salvelinus namaycush) that does not have exactly the same biological characteristics is supposed to have led to a major shift in brown bears, that could not feed on the new trout and started feeding on elks, reducing their population and leading to potential changes in general land cover due to insufficient grazing (Middleton et al. 2013). None of these species is seriously threatened, and apart from the cutthroat trout they are all abundant in Yellowstone, but a minor alteration of a biological process in the ordinary biodiversity led to major changes in the community (including charismatic species), with potential repercussions at the landscape level.

13 Abundance goes along with diversity too. Genetic, epigenetic and adaptive diversity is higher in abundant species, and for that reason they hold the highest evolutionary potential. Then, they are among the most likely to adapt to changes such as climate warming or events like massive epidemics, and then to buffer the effects of perturbations on the community and ecosystem. To adapt to global change, ordinary species must stay abundant, diverse and healthy: this implies not only a good diversity inside the 
population ( $\beta$-diversity), but also a good connectivity with other populations of the same species, with a different genetic pool ( $\gamma$-diversity). Strong population isolation as it can be observed in many protected areas is supposed to lead to genetic impoverishment even when the population seems abundant and healthy, and weakens its potential of response to pressures. Thus conservation projects have to set up multiscalar networks, allowing genes to flow through the populations under protection. And once again, unprotected, non-spectacular landscapes seem crucial to conserving more famous species and ecosystems.

\section{Functional processes}

One could propose that ecosystems can also experience major perturbations along with very limited community level changes, at a large scale. Due to adaptive plasticity (which is, once again, more important in ordinary species), with exactly the same community many different ecosystems can thrive. Here comes again the example of Yellowstone: the elk population depends on the availability of fish for bears. Without any shift in species, climate warming could force the trout to live deeper, away from bears' claws. Then, bears would be forced to eat more elk, and their population decrease would probably affect the vegetation more than the climate warming alone. In other words, with the same bricks, many different local buildings can be built, some being steadier than others, and in an ecosystem plasticity might be just as important as changes in species composition.

The functional processes must also be studied and monitored independently of any change of community structure: the stability of interactions between species and between the species and their environment are just as important as their presence. The functional level also leads to another look on the community: some species are in charge of fundamental processes that no other can do (like kelp in north-pacific kelp forest ecosystems), whereas others can be more or less redundant within their community. The conservation of the ecosystem, then, must concentrate on the permanence of these functions, and emphasize the conservation of processes as well as species. Hence, endangered species lists like the IUCN red list are rarely useful for ecosystem monitoring at a local scale, as rarity and functional importance are poorly related (but see Mouillot $e t$ al. 2013).

The state of an ecosystem cannot be assessed just through the number of species it hosts. It also depends on its functional diversity, inherent plasticity, and on the abundance of the different species. For that reason, Michael Soule (1985) proposed three characteristics of «good state" for any ecosystem: ecological complexity, biological diversity and evolutionary potential. All of them are supported by ordinary biodiversity: different assemblages of common « support » species make different ecosystems hence ecological diversity, these allow the development of an important biodiversity and the relations that common species maintain with other populations allow evolutionary potential. Once corrected and compared to scientific standards, tundras and coral reefs can then be compared on the same scale of good state thanks to these factors, whereas they shelter very different numbers of species. Phylogenetic diversity of communities might be a relevant index to assess the state of an ecosystem (see Frishkoff et al. 2014) 


\section{Ordinary biodiversity and people}

17 Aside from its superiority as a frame for analysis of ecosystem change, ordinary biodiversity may matter most because it is so banal: it represents the species that constitute most of the "nature" surroundings people and activities. Ordinary biodiversity composes most of the natural landscapes we live in, and if we think of it as an heritage, its degradation can be compared to the decay of great monuments from the past, reducing the quality of life of people living and working within and around it. But if such cultural and moral aspects may not make everybody feel concerned, there is another man-nature relationship that should: the simple idea that we are all a part of ecosystems, and we depend for our very lives on many biological processes, which are free but not granted, neither eternal. A word has been built on in order to describe this idea: it is the concept of « ecosystem services. »

According to the Millennium Ecosystem Assessment (2005), ecosystem services are the benefits that humans obtain from biological processes for free. Being free does not mean that they don't have any value: for example, a fish stock is the product of an ecosystem, it is in free access but it can be valued, and sold. The MEA describes four main types of ecosystem services: supporting services (like nutrient cycling and soil formation), provisioning services (like wood growing or fish reproducing), regulating services (like climate regulation or water purification), and cultural services (for esthetic or recreational use of ecosystems). Most of these services rely on ordinary biodiversity, especially for supporting or regulating services, which necessitate huge populations to reach their large-scale effect. We will explore the social issues brought by the ecosystem services concept in the following sections.

\section{Human impacts on biodiversity: relationships with HANPP}

Leading scientific surveys is expensive, and cannot be undertaken everywhere. Then, to assess globally the state of ecosystems, anticipate their dynamics, and establish mechanistic relationships between ordinary biodiversity and anthropic pressure, scientists need a global indicator of this residual pressure on biodiversity. Many parameters have been proposed, like population density or agricultural intensity, but these hardly sum up the varying modes and intensities of environmental changes in a satisfactory way.

Helmut Häberl et al. (2007) proposed a new and promising indicator: the Human Appropriation of Net Primary Productivity. The principle is simple: photosynthesis is for the basis of most of ecosystems on Earth. The difference between the potential primary production of photosynthesis, depending on substratum and climate, and the part that remains in the ecosystem, called $\mathrm{NPP}_{t}$, corresponds to what is appropriated by humans. The lower the $\mathrm{NPP}_{\mathrm{t}}$, the scarcier is the primary food available for the ecosystem, decreasing the global abundance of all species. Then, the level of HANPP provides an interesting and sensitive mapping of diffuse human pressures on ordinary species and ecosystems (but excluding specific pressures like hunting, pollution or extirpations).

21 For example, the human trophic level is related to HANPP: feeding on meat demands more vegetal energy than feeding directly on vegetables; then, for the same amount of proteins or energy, far more NPP is demanded for a carnivore diet than for a vegetarian 
one. Therefore, a slight reduction in the main human trophic level could mechanistically help reducing the level of pressure on ecosystems by lowering the demand in production, producing more food at the same time with less land. Hence, decreasing to the level 2 should lead to a reduction of HANPP of $36 \%$, if the demand in food production is not affected by other drivers like biofuel, and if the food production does not have too much side-effect due to pesticide use or deleterious land-use change for crop producing (Bonhommeau et al. 2013). For all these reasons, HANPP alone cannot represent all the different pressures weighing on the ecosystems, but appears as one potential touchstone for global impact mapping.

\section{Reconciliation ecology and core principles of public policies}

The social and ethical issues involved in reconciliation ecology depend in part on the principles of public policies necessary to preserve ordinary biodiversity, from the biophysical viewpoint. Such principles have to take into account remote effects of humans on biodiversity, in space and time, for different social classes and societies. Policies cannot be only sectorial, concerning for example only the agricultural activity, or some areas, because one has to avoid leakages of biodiversity protection (Wu 2000), spillages among classes, societies. Protected areas, for instance, have been shown to redirect anthropogenic impacts to certain -remote- places, rather than to reduce the overall impact.

The equation I=PAT aggregates and qualifies the effects of human activities on the environment (I), distinguishing the three drivers of human pressures on biodiversity i) the size of the human population (P), ii) the affluence, or the rate of consumption of commodities (A) per individual, iii) the efficiency of human activities, that is the impact on ecosystems to fulfill given human needs, which depends in particular on the techniques (T) used (Daily \& Ehrlich 1992). Considering the human drivers of such impacts, three types of public policies can be distinguished, capping human activities, improving social equity and efficiency of human uses of ecosystems (Daly \& Farley 2010), addressing different social values.

\section{The overall importance of capping human activities}

To determine how much human activities ought to be capped, the scale of human activities has to be compared to the rates of regeneration of ecosystem entities, and to the rates of integration by ecosystems of human outputs, like pollutants of greenhouses gases. Such scale determines how much biodiversity will remain, due to the common dependence of humans and biodiversity on the same ecosystem resources, space, water, light or nutriments. HANPP (see above) as an indicator takes notice of such common dependence. As a matter of fact, cases where significant human impact coexists with an increase of overall biodiversity, measured in biomass terms, have been rare, with the significant exception of arid, irrigated, areas (Häberl et al. 2007).

Agreeing to cap human activities is a very contentious political issue, at least for two reasons. 1) Considering there are limits to the scale of human activities would be a major anthropological change. Selection within and among societies has generally lead to the 
opposite direction, with a selection towards an increase of the use of natural resources (Lenski 2005). Thus, one might consider that human ingenuity has been able to solve any environmental problem and is exponentially increasing, so that biophysical limits of human activities are far from being reached. 2) On a more technical side, such limits are difficult to assess. Limits might vary with the biodiversity component, the temporal horizon, considered.

\section{Relationships between capping human activities and other principles for public policies}

Considering that human activities have to be capped leads to examining the equity issue. The access to ecosystems of the poorest humans determines human pressures, hence the dynamics of ordinary biodiversity. Thus, the frontiers of justice (Nussbaum, 2006), examining equity among human generations, between the human species and the other species, are important social issues to consider. At the opposite of capping the scale of human activities, improving efficiency of economic activities is a well accepted political objective, appropriated by the economic actors. Such improvement is supposed to lead to technologies development, to be a source of competitive advantage, between societies, social groups. However, increasing efficiency of human activities without capping the scale of human activities can lead to the 'rebound' effect, or an increase of such scale. The reason being that higher efficiency stimulates the extension of human activities, because for a same environmental impact, the immediate human benefit increases (Alcott, 2008).

Overall, to stop the decline of ordinary biodiversity, working on efficiency should not overlook the prime importance of capping human activities.

\section{Biodiversity values}

As capping human activities would be a major anthropological change, to legitimate such change requires major arguments in favor of the preservation of ordinary biodiversity, matching at least with the social importance of human activities impacting biodiversity. The strength of such arguments depends on the social relevance of biodiversity values.

In this regard, several typologies for biodiversity values have been developed. The most important and simplest one distinguishes intrinsic and extrinsic - relative to humans values. Intrinsic value of biodiversity has been widely considered in environmental ethics (e.g. Singer 2011), and has been effective to preserve threatened species (i.e. Rodrigues, 2006). When the diversity of social uses of biodiversity and associated values is considered, such typology might not be sufficient, and the ecosystem services typology might be helpful.

\section{Trade-off between provisioning and regulating services}

30 An important aspect of this latter typology is to distinguish on one side provisioning services, associated to commodities or ecosystem goods. These are the bases of human activities, involved in food, water, clothes, fuels, housing... In most societies, commodities are involved in markets, politically regulated. 
31 On the other side, are present most regulating and support services (pollination most often, water purification, climate regulation, for example through carbon storage...), which are not commoditized, usually not appropriated, being public goods. However, these services are impacted by the extension of provisioning services, as shown on empirical and theoretical grounds (MEA 2005). There is also a biophysical trade-off between these two bundles of ecosystem services, provisioning and regulation/support services, as suggested by their differences of dynamics (MEA 2005), and because these services are preferentially associated to different ecosystems, biological communities.

\section{Relationship between regulating services and ordinary biodiversity}

32 The fate of ordinary biodiversity is especially linked to the fate of regulation/support services, because these services are preferentially associated with natural ecosystems, that is ecosystems with light anthropic activities, wetlands, forests...(MEA 2005), ecosystems which are rich in regards to ordinary biodiversity (e.g. Gaston et al. 2003). Moreover, these services are not domesticated, optimized, with the use of few species, but are rather associated to a large biological diversity. Ordinary biodiversity in these ecosystems -genetic and species diversity- should directly benefit to these services, through the biodiversity-ecosystem functioning relationship (Balvanera et al. 2006); diversity should also provide adaptive abilities to global change for these services.

The contribution of ordinary biodiversity to provisioning services might be less clear; an inverse relationship has been suggested, based on the observation of low diversity in high-performance agroecosystems. Beyond the fact that such negative relationship has not been clearly established, positive associations might appear at larger spatial and temporal scales (and see Cardinale et al. 2012).

\section{Social choice involving ordinary biodiversity, the different types of ecosystem services}

34 As a result of these social and biophysical tradeoffs, ambiguity bedevils the ambition to improve ecosystem services. Such improvement might mean two opposite social projects, determining the type of ecosystem favored. 1) On one side, extending commoditization of nature, that is extending the production of ecosystem goods, thus the extent of agroecosystems, plantations, aquaculture or fishing grounds. 2) At the opposite extending non-exploited ecosystems, forests, wetlands..., considering that commoditization of nature should be reduced.

Thus, one has to pounder the social, ethical, relevance of these two possibilities. Some economical concepts might help to analyze the social issues involved.

\section{Units to quantify the social importance of ordinary biodiversity}

From an economical view-point, due to this double trade-off, non commoditized services and ordinary biodiversity can decline as a result of market failure, or negative externalities of market activities. In other words, an overextension of the commoditization of nature will result if such externalities are not taken into account socially. A major question is the extent of such market failure, thus the social importance to preserve regulating services and ordinary biodiversity. Notice that estimating that 
market failure is very large is not an argument for market extension, especially since markets have difficulties to integrate non-appropriable units. Large markets failures rather indicate that markets ought to be regulated to take into account the social importance of maintenance, restoration, of ordinary biodiversity for humans.

There are several difficulties in quantifying the social importance of market failures, hence of ordinary biodiversity. Quantification requires a good understanding of the functioning of the socio-ecosystem considered, of the relationship between biological entities and human aspirations, and requires defining inter-generational equity in regards to these entities (Dasgupta 2013). Uses of such quantification are diverse, from raising awareness, making national accounts, devising sectorial policies, making contracts for instance payments for ecosystem services (Costanza et al. 2014). Another such use is cost-benefit analysis, an important (if imperfect) tool for social choice. Such use requires us to aggregate individual preferences, a difficult task, but for which some tools do exist (Sen 2009).

Monetary units are a rather obvious choice for quantification. These units are involved in a major social activity, markets, in numerous social decisions. As a result, their meaning might, seem, at least superficially, relatively easy to be appropriated by many different humans. Diverse techniques of monetary evaluation exist, hedonic pricing, the cost of restoration or maintenance... (Heal 2000). They most often rely on revealed preferences, which are people behavior towards such entities, to estimate the effect of a loss of such entities for humans.

A major difficulty with monetary evaluations is their potential to be tautological, neglecting the social importance of biodiversity, because such evaluations assume the present societies functioning, where the values of biodiversity might be widely discounted. At the opposite, significant social actions in favor of biodiversity might significantly increase the revealed preferences for biodiversity. Declared preferences are an alternative when social preferences are poorly revealed through social exchanges, a frequent phenomenon in regards to ecosystems in the present social context. Indeed, the willingness-to-pay for biodiversity preservation, a method to reveal preferences for biodiversity, questioned for its consistency with biodiversity values represented, the difficulties of accounting for socio-cultural, and spatio-temporal, variations, can bring very significant values (see Pearce 2002).

Another reason to question the relevance of monetary units is that respective market and political decisions are made based on different criteria, have different logics, thus might have different relevant units. Actually, ordinary biodiversity matters for widely different human aspirations, difficult to aggregate with a single unit. In other words, quantification requires at first identifying non-commensurable human aspirations, then to determine the relevant units in regards to these different dimensions,. That concerns health, education, quality of life... For these human life dimensions, monetary units might not be a very accurate method of quantification (but see Muller 2014).

Overall, the social importance of biodiversity through these quantitative estimates likely remains under-estimated for several reasons, key among which are these two : 1) Only biodiversity components for which information is available are taken into account; for example the extent of forests or fish stocks (e ;g. Arrow et al. 2012) ; less easily measured indicators such as soil fertility or health of pollinator communities are not taken into account, leaving out many biodiversity components which are declining (note : a further 
difficulty would be to get units to aggregate the value of these different assets). 2) Biodiversity values for which human preferences are difficult to estimate are not accounted; this concerns especially biological diversity. Actually, quantifying the social importance of biological diversity per se might be especially difficult, because its importance is very large and diffuse (Bateman et al. 2013).

We will now examine how these quantifications might inform social choice, through the natural capital and shadow price concepts, using cost-benefit analyses.

\section{Natural capital, Pricing, and Sustainability through Ordinary Biodiversity}

43 In the economical line of reasoning, human life is considered to depend on different sorts of capital. Among them, natural capital has been complex to apprehend. Defined as a 'mosaic of self-regenerating but degradable assets' (Dasgupta 2013), it features biological diversity as a central asset. Measuring spatial and temporal variations of natural capital estimates the dynamics of what constitutes the basis of our material life, whose critical transitions in the past have lead to major social difficulties (Diamond 2005). Thus, variations of natural capital are also supposed to give clues on sustainability, for which at least human and manufactured capital should grow faster than natural capital decreases (Mäler \& Dasgupta 2004). Natural capital computations illustrate north-south differences, as overall capital would be decreasing in several southern countries, and are not compensated by the increase of human capital. On the other hand, northern countries would increase their natural capital increase, due to imports of natural capital from southern countries (Arrow et al. 2012). Notice that for such conceptualization of biodiversity as natural capital to be meaningful, an important necessary condition is that natural capital can regenerate. In other words, such capital must remain over a minimal sustainable value or a 'safe minimum standard' (SMS). Such SMS should correspond to an abundance of biodiversity, for example in terms of populations and communities abundance and diversity.

44 Another easier possibility for quantification is to compute the marginal importance of biodiversity for humans, with shadow prices. That concerns small biodiversity variations, which are not endangering biodiversity renewability and/or the viability of human life. Such a method is especially suitable for comparing different policies, affecting biodiversity only at the margins. Notice that mechanisms of variation of shadow prices and real prices differ fundamentally. Real prices result from a dialectics between buyers and sellers, where each one tries to be at the short-hand of the market, that is to have the initiative in regards to the transaction, thus to impose preferences, often with the help of political institutions (Bowles 2004). A shadow price should increase when the asset considered is close to its critical natural capital value, below which sustainability is not assured (Ehrlich \& Goulder 2007). However, as minimal values for natural capital, below which sustainability is not possible, have not been established, such possibility is usually not accounted, underestimating shadow prices.

Nevertheless, minimal shadow pricing is possible for many ecosystem entities associated to biological diversity. Cost-benefit analyses using rough shadow prices estimates, support arguments to preserve both biodiversity and ecosystem components. For example, Batemann et al. (2013) suggest that UK should restrict its agricultural activities, to favor carbon storage by ecosystems, green areas and natural parks, favoring the 
maintenance of biological diversity, because a significant increase of welfare would result at the scale of the nation. Similar exercises in other ecosystems lead to the same kind of conclusion (see Turner \& Daily 2008).

\section{Conclusion: social norms and biodiversity values, perspectives brought by the capability approach}

Relying on preferences to evaluate ethical, social, values of biodiversity is not sufficient. Preferences are highly dependent on the social context, and opportunities, freedom, are not taken into account. Thus, beyond evaluating partially their importance through preferences, biodiversity values have to be integrated in a 'quality of life' model, to guide political choice.

Such 'quality of life' model will be associated to social norms, the ways they take into account environmental quality, and in particular the state of ordinary biodiversity.

The capability approach, a normative framework for human aspiration is an interesting normative possibility to integrate biodiversity values in social decisions (see Polishchuk \& Rauschmayer 2012). In particular, the capability approach considers that maximization of human wealth, in terms of goods and services, is a poor representation of human aspirations.

The capability approach offers the possibility to reassess the importance of ordinary biodiversity, to take into account its different values, to give universals, hence to fuel efficient preservation practices. Indeed, Nussbaum's central capabilities (2000) suggest at least two types of powerful arguments in favor of preservation of ordinary biodiversity. 1) Major capabilities, health, senses, emotions, satisfaction of life..., depend on the state of ordinary biodiversity, which might be considered as a meta-capability, like the ecological carrying-capacity (Holland 2008). 2) The affiliation with other species, the ability to cohabit with them, underlying the intrinsic value of biodiversity. Overall, the capability approach could significantly change the criteria of social decisions, leading to take more into account human aspirations associated with non market activities, in particular human aspirations associated with the state of ordinary biodiversity.

From a more technical view-point, capability indicators would be useful, taking into account the stage of biodiversity. The capability approach has already lead to a new indicator, the HDI, integrating longevity, education and material wealth. However, the HDI does not integrate the state of biodiversity as a meta-capability, and as a matter of fact, remains highly correlated with GDP (Srinivasan 1994). Thus, a BHDI (biodiversity and human development index), taking into account the state of ordinary biodiversity, its social relevance for the different central capabilities, would have to be developed.

51 To become a universal normative framework, the capability approach has to encompass the different biodiversity components, social and ethical issues, taking into account competing moral views, within and among societies, across cultures. Universals are for example necessary for negotiations between northern wealthy but biodiversity-poor countries and southern biodiversity rich countries. Such universals are in particular necessary in situations of 'friction' between different cultures, (Tsing 2005), and should have a central relevance for international negotiations. 

should integrate public choice theory the different forms of democratic representations, beyond representative forms (Rosenvallon 2008) in particular participatory forms. In this regard, one can notice that public policies to preserve biodiversity have been identified, but are not enforced (see for example Peer et al. 2014). The reasons for such political failure - a gap between the scientific and the social spheres, or between the social and the political spheres... - might determine the feature of the political framework to improve.

The authors thanks Rebecca Hardin for many useful suggestions to improve the manuscript.

\section{BIBLIOGRAPHY}

Alcott B. 2008 - The sufficiency strategy: Would rich-world frugality lower environmental impact? Ecological Economics 64 : 770-786.

Arrow K. et al. 2012 - Sustainability and the measurement of wealth. Environment and Development economics $17: 317-353$.

Balvanera P., Pfisterer A.B., Buchmann N., He J.S., Nakashizuka T., Raffaelli D. and Schmid B. 2006 - Quantifying the evidence for biodiversity effects on ecosystem functioning and services. Ecology Letters 9 (10) : 1146-1156.

Ballouard J.-M., Brischoux F., \& Bonnet X. 2011 - Children Prioritize Virtual Exotic Biodiversity over Local Biodiversity. PloS One 6 (8) : e23152. doi :10.1371/journal.pone.0023152.

Bateman I. et al. 2013 - Bringing Ecosystem Services into Economic Decision-Making : Land Use in the United Kingdom. Science 341 (6141) : 45-50.

Bonhommeau S. et al. 2013 - Eating up the world's food web and the human trophic level. PNAS 110 (51) : 20617-20620.

Bowles S. 2004 - Microeconomics : Behavior, Institutions, and Evolution. Princeton N.J., Princeton University Press.

Boyles J., Cryan P., McCracken G., \& Kunz T. - Economic importance of bats in agriculture. Science 332 (6025) : 11-12.

Cardinale B.J. et al. 2012 - Biodiversity loss and its impact on humanity. Nature 486 : 59-67.

Costanza R. et al. 2014 - Changes in the global value of ecosystem services. Global Environmental Change $26: 152-158$.

Daily G.C. \& Ehrlich P.R. 1992 - Population sustainability, and Earth's carrying capacity. BioScience 42 (10) : 761-771.

Daly H. \& Farley J. 2010 - Ecological Economics: Principles and Applications. Washington DC, Island Press.

Dasgupta P.S. 2013 - The nature of economic development and the economic development of nature. Working paper. 
Devictor V., Julliard R., Clavel J., Jiguet F., Lee A. \& Couvet D. 2008 - Functional biotic homogenization of bird communities in disturbed landscapes. Global Ecology and Biogeography 17 : 252-261.

Diamond J. 2005 - Collapse: How Societies Choose to Fail or Succeed. New York, Viking Penguin.

Dirzo R. et al. 2014 - Defaunation in the anthropocene. Science 345 (6195) : 401-409.

Dornellas et al. 2014 - Assemblage Time Series Reveal Biodiversity Change but Not Systematic Loss. Science 344 (6181) : 296-299.

Ehrlich P. \& Goulder L.H. 2007 - Is current consumption excessive ? A general framework and some indications for the United States. Conservation Biology 21 (5) : 1145-1154.

Frishkoff L.O. et al. 2014 - Loss of avian phylogenetic diversity in neotropical agricultural system. Science 345 (6202) : 1343-1346.

Gaston K.J., Blackburn T.M. \& Goldewijk K.K. 2003 - Habitat conversion and global avian biodiversity loss. Proceedings of the Royal Society, Biological Sciences 270 (1521) : 1293-1300.

Häberl H. et al. 2007 - Quantifying and mapping the human appropriation of net primary production in earth's terrestrial ecosystems. PNAS 104 (31) : 12942-12947.

Heal G. 2000 - Valuing ecosystem services. Ecosystems 3 (1) : 24-30. doi:10.1007/s

Holland B. 2008 - Justice and the Environment in Nussbaum's « Capabilities Approach ». Why Sustainable Ecological Capacity Is a Meta-Capability. Politic Research Quaterly 61 (2) : 319-332.

Hughes J., Daily G. \& Ehrlich P., 1997 - Population diversity : its extent and extinction. Science 278 : 689-692.

Lenski G. 2005 - Ecological-Evolutionary Theory: Principles and Applications. Paradigm Publishers.

Mäler K.G. \& Dasgupta P. 2004 - Environmental and Resource Economics : Some Recent Developments. Beijer Discussion Paper.

Middleton A., Kauffman M. \& McWhirter D. 2013 - Animal migration amid shifting patterns of phenology and predation: lessons from a Yellowstone elk herd. Ecology 94 (June) : 1245-1256.

Millenium Ecosystem Assessment, 2005 - Ecosystems and human well being : a framework for assessment. New York, Island Press.

Mouillot D. et al. 2013 - Rare Species Support Vulnerable Functions in High-Diversity Ecosystems. Plos Biology 11 (5) : e1001569. doi :10.1371/journal.pbio.1001569

Muller N.Z. 2014 - Boosting GDP growth by accounting for the environment. Science 345 (6199) : 873-874.

Nussbaum M.C. 2000 - Women and Human Development : The Capabilities Approach. Cambridge, Cambridge University Press.

Nussbaum M.C. 2006 - Frontiers of justice : disability, nationality, species membership. Cambridge, Massachusetts, The Belknap Press Harvard University Press.

Pearce 2002 - An Intellectual History of Environmental Economics. Annual Review of Energy and the Environment 27 : 57-81.

Peer G. et al. 2014. EU agricultural reform fails on biodiversity. Science 344 (6188) : 1090-1092.

Pereira H., Navarro L.M., Martins I.S. 2012 - Global Biodiversity Change : The Bad, the Good, and the Unknown. Annual Review of Environment and Resources 37 : 25-50. 
Polishchuk Y., Rauschmayer F. 2012 - Beyond « benefits » ? Looking at ecosystem services through the capability approach. Ecological Economics 81 : 103-111.

Rodrigues A.S.L. 2006 - Are global conservation efforts successful ? Science 313 (5790) : 1051-1052. Rosanvallon P. 2008 - La contre-démocratie. La politique à l'âge de la défiance. Paris, Points. (Essais). Rosenzweig M. 2003 - Win-win Ecology, How the Earth's species can survive in the midst of human enterprise. Oxford, UK : Oxford University Press.

Sen A. 2009 - The idea of Justice. Penguin Books.

Singer P. 2011 - Practical ethics. Cambridge University Press.

Soulé M. 1985 - What is conservation biology? BioScience 35 (11) : 727-734.

Srinivasan T. N. 1994 - Human Development: A New Paradigm or Reinvention of the Wheel? American Economic Review 84 (2) : 238-243.

Tsing A.L. 2005 - Friction: An Ethnography of Global Connection. Princeton, N.J. : Princeton University Press.

Turner R.K. \& Daily G.C. 2008 - The Ecosystem Services Framework and Natural Capital Conservation. Environmental and Resource Economics 39 : 25-35.

Venter O. et al. 2014 - Targeting Global Protected Area Expansion for Imperiled Biodiversity. Plos Biology 12 (6) : e 1001891. doi :10.1371/journal.pbio.1001891.

Wu J. 2000 - Slippage Effects of the Conservation Reserve Program. American Journal of Agricultural Economics 82 (4) : 979-992.

\section{NOTES}

1. See for example the famous example of the Catskills, supplying the city of New York (Heal 2000 ) .

\section{ABSTRACTS}

Reconciliation ecology aims to preserve ordinary biodiversity through integration of ecology and social values. We define such biodiversity as an alternative to species and site specific conservation approaches, demonstrating its analytical power to understand the dynamics of biodiversity changes, its consequences, in particular in regards to the fate of regulating ecosystem services. We then examine its potential for social legitimacy through a review of philosophical and policy frameworks. We pay particular attention to the representation of ordinary biodiversity's extrinsic values, and to the most appropriate social norms for integrating these into new practices of conservation, based on the potential of the capabilities approach.

L'écologie de la réconciliation a comme ambition de préserver la biodiversité ordinaire. Nous examinons la définition biologique de cette dernière, les raisons de la préserver, son association préférentielle avec les services écosystémiques de régulation. Nous examinons ensuite les 
principes des politiques publiques qui pourraient permettre de la préserver, les valeurs de la biodiversité ordinaire susceptibles d'avoir la plus grande légitimité sociale, les manières de représenter ces valeurs, les normes sociales les plus à même de prendre en compte ces valeurs, et examinons à ce titre les possibilités offertes par les capabilités.

INDEX

Mots-clés: biodiversité ordinaire, écologie de la réconciliation, valeurs de la biodiversité, services écosystémiques et biodiversité, biodiversité et capabilités

Keywords: ordinary biodiversity, reconciliation ecology, biodiversity values, ecosystme services and biodiversity, biodiversity and capabilities

\section{AUTHORS}

DENIS COUVET

UMR CESCO, CP 51, 55 rue Buffon, 75005 Paris

\section{FRÉDÉRIC DUCARME}

UMR CESCO, CP 51, 55 rue Buffon, 75005 Paris 